\title{
CENTRO DE APOIO À INCLUSÃO ESCOLAR DE CRIANÇAS E JOVENS AUTISTAS NA CIDADE DE BAURU - SP
}

\author{
Beatriz Góes de Souza ${ }^{1}$ \\ André Luiz de Oliveira Chaves ${ }^{2}$
}

\begin{abstract}
RESUMO: A proposta do trabalho trata-se de um estudo que se refere a um Centro de Atividades para autistas no município de Bauru, interior do Estado de São Paulo. O conteúdo tem como apoio bibliografias e uma ampla pesquisa, tais como, conversa com profissionais $\mathrm{d}$ a área, dentre eles professores e médicos, visita técnica, busca por centros de atividades já existentes, que colaboraram com o estudo que pode comprovar a influência da arquitetura no desenvolvimento da criança e jovem com transtorno do espectro autismo. Desta maneira, o objetivo é trazer um novo proje to de centros de atividades e desenvolvimento para quem possui este transtorno e em seguida rever as formas de transformar e ensinar as modalidades de aprendizagem aplicados dentro desses locais, de maneira que a arquitetura contribua e colabore para o desenvolvimento e conforto de cada criança e jovem com o transtorno do espectro do autismo.
\end{abstract}

Palavras chaves: Projeto de arquitetura. Autismo. Centro de atividades. Bauru.

ABSTRACT: The proposal of the work is a study that refers to an Activity Center for autistic people in the city of Bauru, in the interior of the State of São Paulo. The content is supported by bibliographies and extensive research, such as, conversation with professionals in the field, among them professors and doctors, technical visit, search for existing activity centers, who collaborated with the study that can prove the influence of architecture in the development of children and young people with autism spectrum disorder. In this way, the objective is to bring a new project of centers of activities and development for those who have this disorder and then to review the ways of transforming and teaching the learning modalities applied within these places, so that the architecture-contributes and collaborates for the development and comfort of each child and youth with autism spectrum disorder.

Keywords: Architectural design. Autism. Activity center. Bauru.

\section{INTRODUÇÃO}

O transtorno do espectro do autismo (TEA) vem crescendo cada vez mais no mundo todo, de forma global. Isso pode se observar nos Estados Unidos, onde em 2000 havia uma criança autista a cada 150 nascidas, em 2014 os números aumentaram razoavelmente de uma criança autista para cada 59 nascidas e em 2018 os números já eram de uma criança autista para cada 44 nascidas (CDC, 202I). Ainda não se descobriu uma

\footnotetext{
'Arquiteta e urbanista (recém-formada), aluna do curso de Arquitetura e Urbanismo na Universidade Paulista - Campus de Bauru - SP até dezembro de 2021.

${ }^{2}$ Arquiteto e urbanista, Professor Doutor do curso de Arquitetura e Urbanismo na Universidade Paulista Campus de Bauru - SP.
} 
causa única para o crescimento do TEA, e apesar do acesso à saúde nos dias atuais ser mais fácil, ainda existem pessoas que não conseguem receber o diagnóstico (SOUZA, 2021).

Segundo Oliveira (2021), pelos dados do CDC, estima-se que o Brasil possua atualmente cerca de 2 milhões de autistas, sendo mais de 300 mil ocorrências só no Estado de São Paulo. Contudo, apesar de numerosos, os milhões de brasileiros autistas ainda sofrem para encontrar tratamento adequado, pois, ainda não existem pesquisas aprofundadas e permanentes diante o transtorno. A Lei 13.861/19, sancionada em 2019 obrigou o Instituto Brasileiro de Geografia e Estatística (IBGE) a inserir no Censo 2020 perguntas sobre autismo. Pesquisas como esta ajudam a localizar e dar visibilidade para mais estudos sobre o TEA no país.

Dentro deste contexto, o acesso do aluno com TEA no ambiente escolar merece atenção especial, sendo que normalmente ocorrem conflitos gerados pelo seu comportamento ao ingressar em um grupo social no qual a interação com outras pessoas na mesma faixa de idade é forçada. Pois, todas as crianças e jovens autistas exibem grande deficiência no campo da interação social, uma vez que não possuem a capacidade empática para interpretar sentimentos dos outros. No que diz respeito à relação com o ambiente em que estão inseridos, alguns dos transtornos causados pela síndrome dificultam, ou impedem, a interação deles com o espaço construído à sua volta (VASCONCELLOS, 2020).

Quanto à cidade de Bauru, local do objeto deste estudo, a demanda de crianças e jovens com TEA que freqüentam as salas de aula têm crescido muito. Pois, apenas nas escolas da rede municipal de ensino em 2019, foram diagnosticados 150 alunos com autismo, enquanto que em 2010 eram apenas 22 alunos diagnosticados. Naquela época, a rede dispunha de 128 professores especializados e 107 cuidadores para dar assistência tanto aos alunos com TEA como aos alunos com outro tipo de deficiência neurológica, e que totalizavam 66i pessoas (LOUSADA, 2022).

Para a inclusão de crianças e jovens autistas nas escolas regulares e no mercado de trabalho, a cidade de Bauru conta com o apoio de associações e instituições que realizam o atendimento e diagnóstico destas pessoas, como é o caso da Associação de Pais e Amigos dos Excepcionais (APAE), do Centro de Atenção Psicossocial (CAPs), do Centro Especializado em Reabilitação SORRI-Bauru e da Associação dos Familiares, Amigos e 
Pais dos Autistas de Bauru (AFAPAB). Entretanto, mesmo tendo profissionais especializados para dar a devida atenção às pessoas com TEA, a APAE, a CAPs e o SORRI-Bauru não são específicos apenas no tratamento do autismo, pois atendem crianças e adultos com deficiência intelectual, TDAH, dislexia, deficiência física e motora, doenças neurodegenerativas, lesão encefálica, entre outros casos.

Destas instituições, apenas a AFAPAB oferece atendimento multidisciplinar especificamente voltado às crianças e jovens com TEA, na faixa dos 2 aos 18 anos. Esta instituição tem atuação em três frentes: assistência, educação e saúde. $\mathrm{Na}$ área da saúde oferece um importante trabalho de atendimento pediátrico gratuito e diagnóstico precoce de autismo para os portadores e as famílias. $\mathrm{Na}$ área da educação o local mantém a escola especial do autista de Bauru, que oferece escolarização por meio da estrutura adaptada e o currículo de professores voltado às atividades especificas para autistas (AFAPAB, 2021).

Entretanto, apesar de ser direcionada ao atendimento de pessoas autistas, a associação apresenta poucos aspectos positivos como o design sensorial em alguns de seus cômodos e utilização de cores suaves em seus ambientes. Ela contém mais aspectos negativos como o mau isolamento acústico de seus espaços, a falta de separação dos acessos

para funcionários e pacientes e a ausência de boa iluminação natural, apesar de ter recursos para iluminação artificial com projeções de luzes e cores. Tais fatos ocorrem, pois não houve uma intervenção adequada dos ambientes na casa onde a associação foi implantada (SOUZA, 2021).

Ainda que existam instituições e clínicas que disponham de profissionais para o tratamento das pessoas com TEA, há uma grande procura por espaços específicos que prestem tais assistências na cidade de Bauru. Os tratamentos realizados nestas instituições são insuficientes e muitas vezes com o tratamento precário para amenizar os sintomas do autismo. Os locais para as famílias encontrarem os profissionais especializados são escassos e os que existem são de difícil acesso tanto economicamente quanto em relação às filas de espera por serem locais que não possuem estrutura que comporte a demanda da cidade e da região (SOUZA, 2021).

\section{OBJETIVOS}

Com base em contexto anterior, o presente artigo tem como objetivo analisar a proposta de um projeto de centro de vivência/atividades na cidade de Bauru, que seja 
devidamente estruturado e designado a crianças e jovens com TEA, tendo como base as diretrizes de design associadas ao conforto ambiental e acessibilidade inclusiva, para a criação de espaços agradáveis, que influenciem de maneira positiva no comportamento e neurodesenvolvimento das pessoas autistas. De maneira, que tal proposta colabore para a inclusão futura de crianças e jovens no processo de aprendizagem das salas de aula, nas escolas regulares da cidade.

\section{I.I. METODOLOGIA}

A primeira etapa desta pesquisa foi desenvolvida a partir de levantamento bibliográfico, no qual foram coletados dados de livros, artigos, sites, vídeos e bibliografias em geral, sobre assuntos relacionados ao tema do trabalho, para que se pudesse ter o conhecimento de como o transtorno do espectro do autismo pode afetar a família e o seu portador, e como deve ser o ambiente de educação, convivência e lazer para quem possui TEA, de maneira a auxiliar na compreensão de como desenvolver a fundamentação teórica e projeto arquitetônico ideal.

$\mathrm{Na}$ segunda etapa foi pesquisado o Advance Center for Autism, considerado o

maior projeto referencial neste segmento sobre autismo, projetado pela arquiteta Magda Mostafa, selecionado em site especializado, e no qual foram analisados: implantação, programa de necessidades, acessos, acústica, ventilação, iluminação, fluxos de pessoas, técnicas construtivas, partido arquitetônico, e outros. $\mathrm{Na}$ terceira etapa foi realizado levantamento de campo, para a coleta de informações e análise a partir de visita técnica à AFAPAB em Bauru. Por fim, foi desenvolvida a proposta de um projeto de centro de vivência/atividades para autistas, com capacidade de dar suporte a profissionais especializados.

\section{FUNDAMETAÇÃO TEÓRICA}

\section{I. Transtorno do espectro do autismo}

O TEA é classificado como um dos transtornos do neurodesenvolvimento e as pessoas que o possuem enfrentam problemas em nível social, como a dificuldade de interagir e se comunicar com outras pessoas, além de apresentarem padrões restritos e repetitivos em seus níveis comportamentais. Existem estudos, cujos resultados mostram que as crianças 
com este transtorno contêm mais hipersensibilidade do que as crianças sem TEA (neurotípicas), fazendo com que as crianças autistas apresentem alteração no processamento sensorial, o que contribui para uma má adaptação de suas respostas comportamentais e de aprendizagem (GUTIÉRREZ; GOMEZ; FERNANDEZ, et al., 2021).

Os sintomas aparecem com diversos graus de severidade, o que determina o grau de autonomia e os prejuízos funcionais, e isso tudo varia conforme o nível de desenvolvimento e a idade cronológica. Existem pessoas que conseguem viver de forma independente com o transtorno, já outras mais severas que precisam do apoio e acompanhamento especializado. A partir dos dois anos de idade pode-se diagnosticar o autismo, porém a dificuldade em encontrar profissionais e locais especializados que dão o diagnóstico, ainda é uma batalha para quem vive no Brasil. Sendo assim a maioria dos diagnósticos são dados apenas após os quatro anos de vida (INSTITUTO NEURO SABER, 2021).

Figura I: Características do autista.

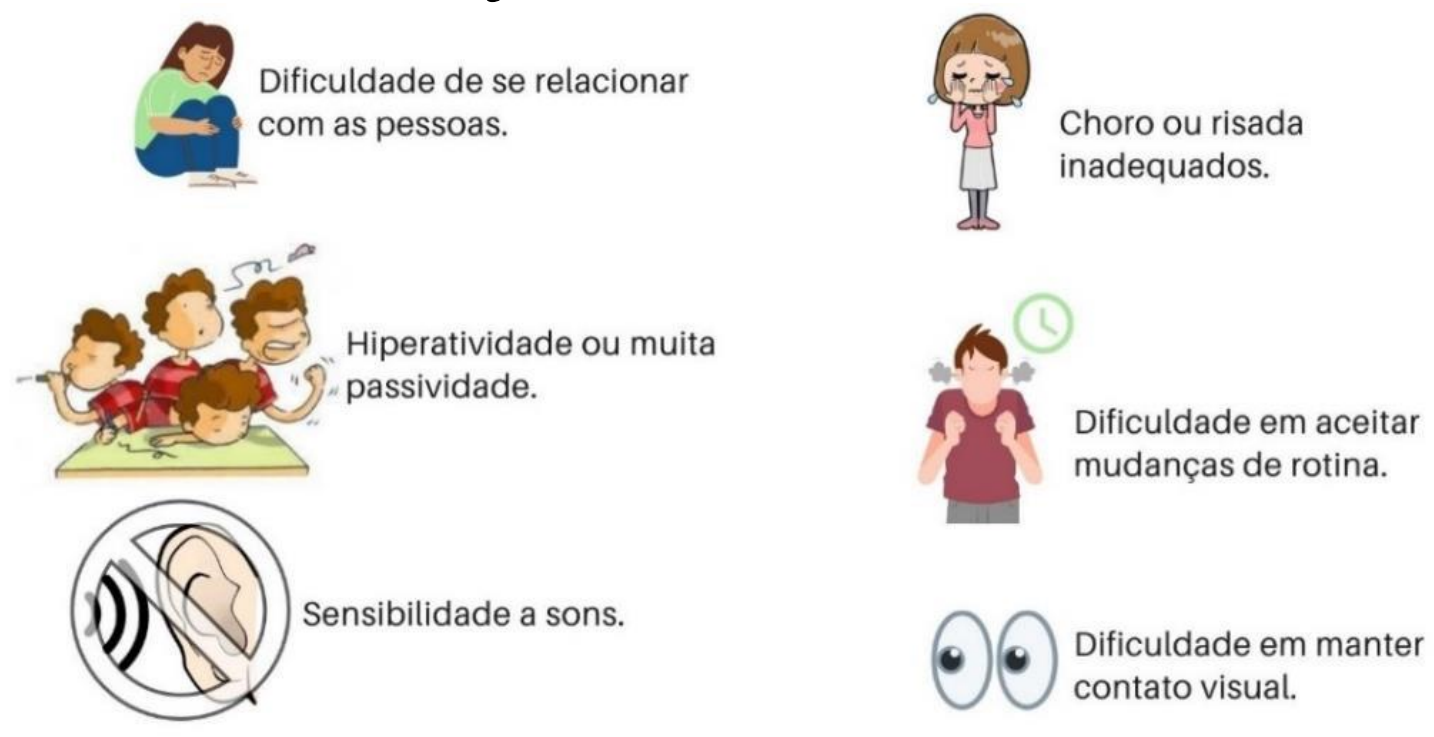

Fonte: Própria autoria, 2021.

\subsection{Transtornos sensoriais}

Segundo Laureano (2017), 90\% das crianças com autismo possuem transtornos sensoriais, sendo mais comuns: os visuais, que é o interesse delas por objetos giratórios, coloridos ou que se movimentam; táteis, que se manifestam através de reações à diferentes texturas e de pouca sensibilidade à dor; auditivas, com hipo ou hipersensibilidade na 
audição; gustativas, que manifestam através de seletividade alimentar e tendência de colocar objetos na boca; cinestésica, que é o gosto excessivo por gritar, balançar, etc.; olfativas, que se manifestam com reaçoes a odores. Como uma solução, há os ambientes sensoriais que tendem a valorizar o âmbito terapêutico, educacional e de lazer, estimulando e/ou desenvolvendo o equilíbrio do sistema sensorial destas crianças.

Gutiérrez; Gomes; Fernandez et al. (2021) citam estudos cujos resultados mostraram que as crianças com TEA possuem distúrbios sensoriais atípicos quando sentem dor; possuem aversão a cheiros incomuns ou objetos desconhecidos; evitam certos sons ou texturas; ou buscam por experiências visuais específicas. Da mesma forma um estudo realizado por Fernández-Andrés, et al. (2015) constatou que as modalidades sensoriais mais afetadas em crianças com autismo foram a audição e o tato, ao terem seus processamentos sensoriais comparados aos processamentos das crianças sem o transtorno; enquanto pesquisas citadas por Ouellet, Carreau, Dion et al. (2021) mostraram que os professores perceberam que os alunos com TEA tinham menor atenção e tolerância à aprendizagem e maior necessidade de auxílio para realizar as atividades do que os alunos com desenvolvimento neurotípicos.

De uma maneira geral, as crianças com transtorno do espectro do autismo necessitam estar em ambiente escolar que seja ajustado sensorialmente para reduzir as suas tendências de hipersensibilidade e facilitar suas autorregulações. No entanto, cada uma delas possui um processamento sensorial diferente e este fato exige que sejam feitas adaptações necessárias no ambiente escolar, seguindo as recomendações de projeto arquitetônico acessível às pessoas autistas, de forma à facilitar seus processos de aprendizagem neste meio.

\subsection{Sensibilidade ao som}

As pessoas com transtorno do espectro autista podem ter reações adversas aos sons existentes nos ambientes, sendo que alguns podem reagir abruptamente a pequenos ruídos, enquanto outros não esboçam reação aos ruídos de grande intensidade. Pois, um dos sintomas de pessoas com muita sensibilidade auditiva é a dificuldade em se regular e controlar o volume do som (HAMADA, 202I). Quanto às crianças com o transtorno, normalmente, possuem intolerância a alguns tipos de sons, que constituem componentes 
essenciais na percepção espacial destas crianças, sendo um dos fatores principais para o transtorno sensorial delas (POSAR e VISTCONTI, 2018).

Em razão desta grande sensibilidade auditiva das pessoas com TEA, recomenda-se que os espaços sejam projetados de forma a reduzir os ruídos, os ecos e a reverberação (ALOCHIO; QUEIROZ, 2020). Em uma sala de aula recomenda-se o uso de película nos vidros das janelas ao invés de cortinas, sendo que estas ocasionam ruído quando balançam; a substituição de ventiladores por aparelhos de ar-condicionado que não emitam ruídos; e cuidados com a localização das salas destinadas às pessoas com TEA (AMARAL; PEINADO, 2020).

Por outro lado, os sons também são capazes de promover mudanças, influenciando capacidades sensoriais, motoras, cognitivas, afetivas e sociais das pessoas com TEA. Através da Musicoterapia, uma prática com música no contexto clínico de tratamento, reabilitação ou prevenção de saúde e bem-estar, pode se utilizar estímulos sonoro-musicais adequado ao paciente, em meio à condição do momento e ao objetivo de tratamento, não necessariamente usando sons de sua preferência (MARANHÃO, 2020).

\subsection{Sensibilidade à luz}

As pessoas hipersensíveis que vivem no espectro do autismo conseguem observar tudo o que está ao seu redor de forma bem detalhada, o que as leva a ter dificuldade no contato visual com outras pessoas, e por isto usam o contato visual periférico para analis ar o espaço que as envolve. Por outro lado, as pessoas hiposensíveis com TEA têm contato visual quase nulo com o ambiente, como se tudo ao redor não tivesse importância ou apenas com a capacidade de ver a silhueta dos objetos (HAMADA, 2021).

A partir deste contexto é importante que a iluminação a ser adotada para as pessoas com TEA seja configurada de maneira que elas tenham maior capacidade de se concentrar ou descontrair ao realizarem suas atividades. Tanto a luz natural quanto a artificial pode ser usada com objetivo de oferecer estímulos que despertem e liberem as percepções sensoriais nas pessoas com o transtorno (ALOCHIO; QUEIROZ, 2020). Também é importante que o ambiente seja projetado de maneira a receber ampla incidência de luz natural, pois isto atribui à pessoa que vive no espectro do autismo uma visão mais nítida do espaço à sua volta. 
No caso das crianças autistas, a iluminação pode proporcionar-lhes uma interação física e lúdica, além de possibilitar que tenham mais foco ou descontração em suas atividades (EPIFÂNIO, 20I8). Associado a isto, é importante que haja iluminação regular dentro de uma sala de aula, se for levado em conta que as zonas de ofuscamento (em virtude do excesso de luz) e/ou de sombreamento (em virtude da falta de luz) podem causar irritabilidades nas crianças com TEA (POSAR e VISCONTI, 20I8, e LAUREANO, 2017). A maioria das diretrizes para um espaço direcionado ao autismo leva em consideração alguns detalhes como reduzir o brilho e evitar a cintilação das luzes fluorescentes (NOBLE, 2018).

\subsection{Sensibilidade às texturas/cores}

As texturas e cores tornam possíveis as atividades táteis e visuais, que auxiliam no desenvolvimento da consciência corporal e cognitiva das crianças autistas. Podem estar associados à identidade visual, códigos de cores, formas simples e identificações a partir de figuras (EPIFÂNIO, 2018). Entretanto, deve-se ficar atento ao fato de que as crianças autistas possuem reações às texturas e cores, pois, tanto contato tátil quanto visual das superfícies pode ser agradável ou não para elas (SILVA; BRASIL; ROLA, 2020).

Segundo Hamada (2021), em um ambiente para pessoas com TEA, os elementos não devem ser revestidos com materiais cujas texturas apresentem muito brilho e reflexo, dando-se preferência ao uso de materiais foscos. Também deve ser criada diferença dos materiais com aspecto liso ou áspero. Devem ser adotados padrões de cores e texturas que não tenham muito contraste e diferença; e as cores devem atender preferencialmente a tons neutros e suaves, devendo ser evitado o uso de muitas cores, pois isto pode causar desconforto em indivíduos hipersensíveis.

De uma forma geral, os tons contrastantes devem ser utilizados para sinalizar objetos específicos ou possíveis riscos, como bordas ou degraus de escadas, ou mesmo uma mudança no tipo de atividade realizada em um determinado espaço. Além disso, há o fato que as cores quentes transmitem a sensação de um espaço menor e agitado enquanto que as cores frias dão a sensação de um espaço maior e calmo (VASCONCELLOS, 2020). Por isto, no ambiente de ensino com alunos com TEA é importante serem adotadas cores reconfortantes que não lhes tire o foco no momento de aprendizagem. 


\subsection{Organização dos espaços}

Uma das características da criança autista é a resistência às mudanças no ambiente, como deslocamento de um móvel ou mudança na rotina cotidiana, e as mínimas alterações podem estimular-lhes reações explosivas. Para a criança com o transtorno os conceitos dentro e fora estão muito ligados, a ponto dela não saber diferenciar estes dois meios. Muitas vezes, ela não percebe os objetos e o espaço que a envolve (LAUREANO, 2017). Assim, organizar o espaço ajuda a melhorar o ambiente como um todo, de maneira que é dada a noção para a criança com TEA do que é cada espaço e como se dá as transições entre eles, tornando o comportamento desta criança menos estressante (HAMADA, 2020).

De acordo com aspectos de projetos identificados em pesquisas de Amaral e Peinado (2020) é recomendável que as cadeiras e mesas sejam reguláveis para se ajustar ao tamanho do aluno, as bordas dos móveis sejam arredondadas e com materiais que absorvam o ruído (ex. material emborrachado); que os mobiliários tenham formatos diferentes (ex.: mesas em formatos retangulares com as bordas trianguladas) para que possam ser dispostos em círculos; conforme o caso, podem haver divisórias móveis para que a sala possa ter seu tamanho ajustado conforme a atividade proposta; não deixar as carteiras muito próximas entre si, visto que crianças com autismo precisam de bom espaço para que possam ser devidamente auxiliados em suas atividades.

Os espaços para as pessoas autistas devem ser concebidos por meio de zonas pensadas para atender às percepções sensoriais de cada uma delas, ao invés de serem estabelecidas zonas para atender aos aspectos funcionais. Por isto, estas zonas devem ser simples e de fácil compreensão para que estas pessoas consigam ter autonomia em suas ações (ALOCHIO; QUEIROZ, 2020). Na organização dos ambientes escolares devem ser levados em consideração os aspectos de hipersensibilidade das crianças com TEA, para que cada um destes ambientes as estimule de maneira certa, dando-lhes respaldo para realizarem as atividades pedagógicas propostas (AMARAL; PEINADO, 2020).

\subsection{Zonas de transição}

As áreas de transição devem ser pensadas de forma que as pessoas com TEA possam ter autonomia e não dependam de outras pessoas as guiando para que sejam orientadas pelo caminho, de maneira que através de uma seqüência espacial, seja gerada 
uma rotina para elas (HAMADA, 2020). Há também o fato de que este sequenciamento espacial consiste em uma organização lógica dos espaços, que devem ser configurados para haver fluidez e tranquilidade entre uma atividade e outra destas pessoas, atendendo à uma programação horária das atividades (ALOCHIO; QUEIROZ, 2020).

Os espaços de transição auxiliam a criança autista no controle de seus sentidos, à medida que se desloca de um nível de estímulo a outro, reagindo com um mínimo possível de stress. Seqüenciar estes espaços significa torná-los previsíveis, o que ajuda a criança antecipar as atividades que irão ocorrer nos espaços seguintes, reduzindo a ansiedade que estas mudanças podem ocasionar. Estes espaços podem ser planejados na forma de um jardim sensorial, de um corredor ou de uma área sensorial (VASCONCELLOS, 2020).

\subsection{Espaços de fuga}

Estes são os espaços, nos quais as pessoas autistas podem se isolar por um determinado tempo e se acalmar para se recompor em relação aos estímulos do ambiente, sendo que elas podem vir a sentir os impactos de vários estímulos que podem lhes causar alterações sensoriais. Estes espaços podem ser uma sala, ou até mesmo uma cabana ou algumas estantes integradas em um espaço maior (HAMADA, 2020). Recomenda-se que estes espaços sejam silenciosos e tenham um ambiente sensorial neutro com o mínimo de estímulos, para que as crianças e jovens com TEA possam se esconder e se retirar para seu “próprio mundo”, assim que necessitarem (VASCONCELLOS, 2020).

\subsection{Espaços externos}

A integração de espaços exteriores no ambiente de aprendizagem é benéfica aos estímulos das crianças e jovens com o transtorno, sendo que proporcionam condições para que eles desenvolvam habilidades associadas à maior autonomia e capacidade de convívio social. Nas escolas, os espaços acessíveis à estas pessoas devem ser planejados de maneira que existam áreas diferentes, separando espaços para atividades barulhentas e espaços para atividades silenciosas. As áreas internas da escola devem ser planejadas para funcionar em conjunto com as áreas externas, proporcionando assim uma variedade de opções de uso às pessoas com TEA, auxiliando-as na compreensão do espaço. Ou seja, os ambientes devem oferecer espaços ao ar livre para recreação e aulas externas (VASCONCELLOS, 2020). 
A relação entre ambientes internos e externos faz com que uma pessoa com TEA desenvolva sua consciência corporal, cognitiva, de maneira que são proporcionadas diferentes percepções e relações entre ela e o meio (ALOCHIO; QUEIROZ, 2020). Por isto, as áreas verdes no ambiente externo, especialmente os jardins sensoriais, podem estimular as crianças a experimentarem texturas, cores e cheiros do ambiente através dos seus sentidos, sendo que estes elementos são projetados para oferecer o máximo de estímulo possível (HAMADA, 2020). Assim, um jardim desta espécie pode transmitir uma sensação de liberdade para as crianças autistas e sentimento de controle para os responsáveis por elas (VASCONCELLOS, 2020).

\subsection{Relação entre autismo e arquitetura}

Para as crianças com o transtorno do espectro do autismo é fundamental frequentar a escola regular, especialmente para sua integração com a sociedade. Contudo, a estrutura física e os métodos pedagógicos utilizados nas escolas tradicionais dificultam a inclusão e aprendizado das crianças que possuem o espectro do autismo. Elas ficam agitadas e se distraem com mais facilidade em ambientes que possuem muitas

informações, muitos estímulos, como nas salas de aulas, que possuem barulhos, excesso de cores e muitas informações diferentes ao mesmo tempo em suas paredes. Nas escolas tradicionais é evidente a falta de preparo na hora de lidarem com este tipo de caso, tanto pela falta de estrutura adequada, quanto pela forma de ensino (BRASIL ESCOLA, 202I).

Através desse cenário, muitos familiares encontram dificuldade ao buscar um auxílio de profissionais especializados que colaborem no desenvolvimento comportamental, cognitivo e nas habilidades das rotinas do dia a dia. Com o auxílio desses profissionais os familiares conseguem estimular as habilidades necessárias para que as crianças autistas possam ter sua vida mais independente possível (SOUZA, 2021).

De acordo com Sassaki (2008), a acessibilidade pode ser dividida em seis formas e ele considera todas elas como importantes e indispensáveis para o processo de inclusão e qualidade. As dimensões propostas são detalhadas da seguinte forma:

- Comunicacional: eliminação de barreiras de comunicação e escrita. A utilização de diversas maneiras, linguagens e línguas que facilitam a comunicação, isso deve ser assegurado no processo de educação; 
- Arquitetônico: eliminação de empecilhos físicos que dificultam o acesso aos ambientes. As adaptações e acessos dos espaços desde a entrada e toda a circulação devem possuir fácil acesso;

- Instrumental: eliminação das barreiras nos utensílios e ferramentas pedagógicas. A adaptação de materiais de maneira que todos utilizem com facilidade nos momentos de aprendizagem.

- Programática: eliminação de barreiras ocultas em políticas públicas, que possam dificultar a participação de todos os indivíduos na vida escolar.

- Metodológica: retirada de barreiras nos métodos pedagógicos e técnicas de estudos.

- Atitudinal: eliminação de atitudes preconceituosas e discriminatórias. A pro moção de atividades na escola e seu entorno que promovem a conscientização da convivência com diversos indivíduos.

Ao se estudar sobre o autismo foram adquiridas algumas características principais para se realizar um projeto especifico, para proporcionar o conforto e acesso adequado para os autistas. A inclusão, seguindo as normas de acessibilidade, treinamento das habilidades de rotinas do dia a dia, possibilitarem a participação da família nos tratamentos. Simplicidade e clareza, ao realizar um projeto que seja com formas arquitetônicas simples, com um layout claro e objetivo, com zoneamento prático e evitando muitas informações para que não cause poluições visuais. O planejamento com padrões generosos de espaços, setorização e layout bem definido. Projeto que colabore com uma integração social, através de salas de baixo estimulo sensorial e com poucas opções de distrações, opções que melhorem o relaxamento e a co-ordenação. Colaborar para evitar o estresse e ansiedade, juntamente com o autocontrole, através do equilibro. Limites físicos e visuais, evitar objetos com arestas pontiagudas, proporcionando segurança e proteção (SASSAKI, 2008).

Nas características construtivas o ideal para a acústica seria utilizar materiais aconchegantes, emborrachados, forro de gesso acartonado e uma manta acústica entre os ambientes. Para o edifício possuir uma ventilação agradável recomenda-se utilizar de aberturas amplas que valorizem a ventilação natural e cruzada. Na iluminação pode-se fazer o uso de dimmers e controladores para ajustar a intensidade da luz artificial e aproveitar o máximo da luz natural. Como o local pode ser muito utilizado o uso de materiais duráveis é uma das características principais, com materiais acessíveis de fácil manutenção (SOUZA, 2021). 


\section{ESTUDO DE CASO}

\section{I. Referência projetual: Advance Center for Autism (2007)}

O Advance Center for Autism foi projetado seguindo a teoria da arquiteta pioneira do autismo (a Magda Mostafa), que tem em mente a teoria do design sensorial. $\mathrm{O}$ edifício está localizado no lado oeste da cidade de Cairo, Egito, em uma área residencial com baixa densidade de construções, definida por edifícios baixos.

Figura 2: Croqui do Advance Center for Autism.

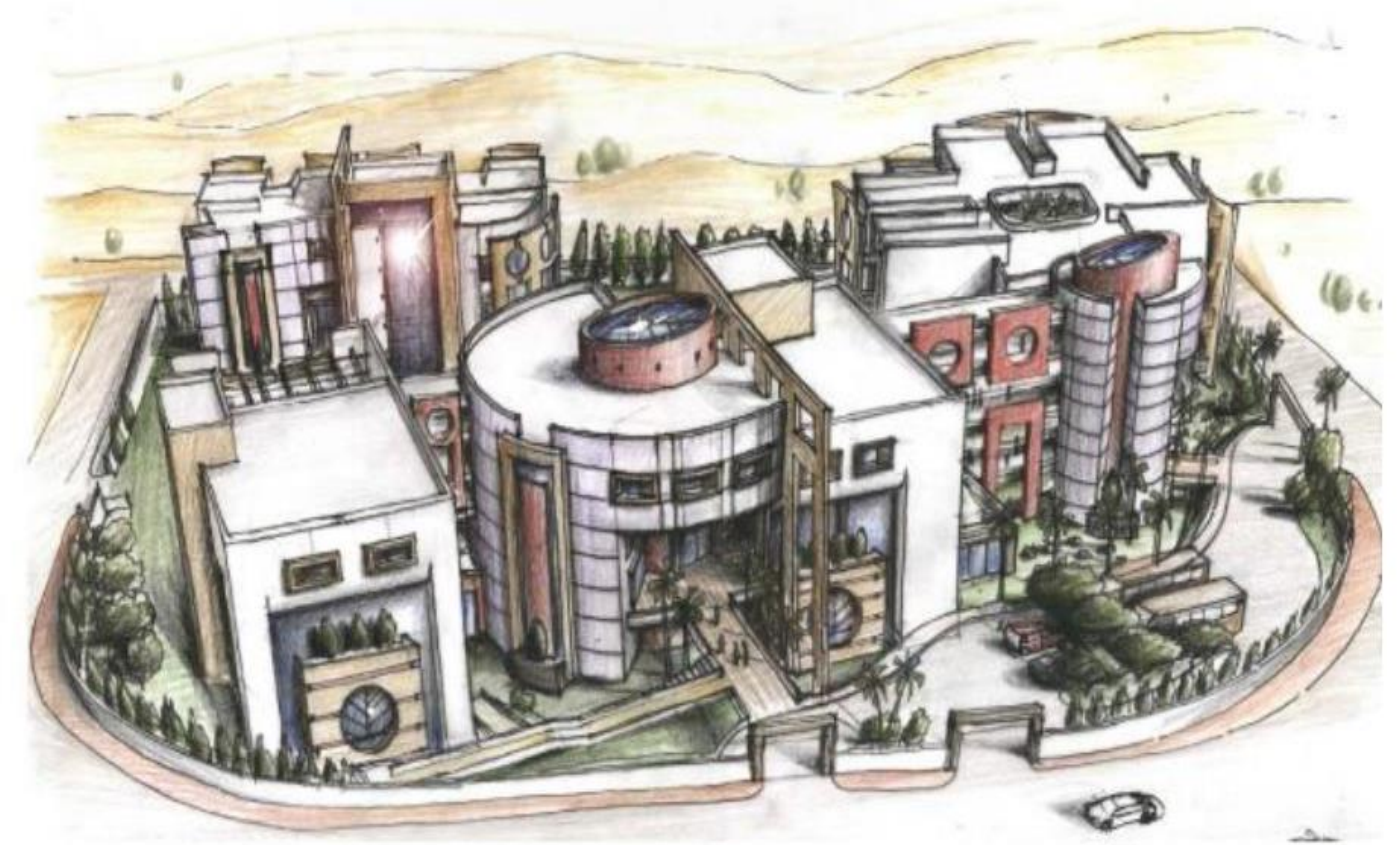

Fonte: MOSTAFA (2008).

Programa de necessidades - O Advance Center é rigorosamente dividido de acordo com seu estimulo sensorial, variando entre área com grande estimulo e área com baixo estimulo sendo conectadas por zonas de transição pensadas como pontes. A construção se divide em quatro edifícios diferentes, sendo eles área desportiva, área de relações públicas, unidades de repouso e o edifício de tratamento, sendo de seis pisos apenas o edifício, voltado aos tratamentos. O local possui duas entradas, que para dar maior intimidade ao núcleo de tratamento são conectadas. Referente ao seu programa ele oferece todo suporte terapêutico e educacional. Os suportes dados são inúmeros, porém para o autista há o suporte necessário através de salas individuais, acomodações e jardins sensoriais. 
Técnicas aplicadas - No ambiente sensorial há o uso de cores suaves, materiais naturais, acústica agradável e iluminação natural torna o ambiente mais agradável e abre caminho para a comunicação e habilidades que possam ser desenvolvidas. Quando projetou estes edifícios, Magda Mostafa levou em consideração sete critérios de design indicados através de entrevistas e pesquisas experimentais sobre o desenvolvimento de pessoas com TEA. Esses critérios foram a compartimentalização, espaços de transição, acústica, sequenciamento espacial, zonas de fuga, zonas sensoriais e de segurança. Segundo Magda esses sete critérios constroem um alicerce para uma matriz de design para autistas que ajudaram a desenvolver soluções especificas e ajudaram a adequação do autista no ambiente construído.

Análise crítica - Neste projeto a arquiteta Magda Mostafa, utilizou o design sensorial de acordo com cada função de seus ambientes. Ela buscou utilizar cores suaves, acústica agradável, detalhe muito perceptivo quando se vai projetar para autistas, pois eles são sensíveis a barulhos, iluminação natural e materiais naturais, em meio aos espaços sensoriais. Nas entradas ela utilizou cores e texturas ajudando assim a chamar a atenção dos autistas para o edifício. O projeto foi realizado com duas entradas: uma somente para os pacientes e outra destinada ao público. Apesar de o Advance Center estar localizado em uma área calma e residencial com grandes áreas verdes e de fácil acesso, ele possui em desvantagem a localização longe de centros médicos e instituições de ensino, com isso o local se torna afastado de sua zona de interesse. Tais detalhes empregados pela arquiteta colaboram positivamente em relação aos espaços e negativamente em relação a sua localização, para a criação de um projeto específico e confortável destinado a autistas.

\section{PROPOSTA PROJETUAL}

Programa de necessidades - foi elaborado com base nas pesquisas realizadas ao longo do trabalho, para maior entendimento das necessidades, atividades e tratamentos adequados à criança que possui o transtorno do espectro autista e aos responsáveis pela mesma. No programa de necessidades foram utilizados os critérios da arquiteta Magda Mostafa. Para determinar as dimensões dos espaços foram realizadas pesquisas na NBR 9050-2015, com aplicações para atender o número de crianças necessário. 
A quantidade de cômodos foi determinada com base na quantidade de pessoas a serem atendidas, contabilizando 600 crianças, com idades entre 2 a 18 anos, cada uma com dois atendimentos semanais. Tendo em vista a demanda por atendimento, o trabalho proposto pretende atender cerca de 650 crianças, cada uma com dois atendimentos por semana no mínimo. O horário de atendimento seria das 8 horas às 18 horas.

O programa foi pensado e dividido em seis componentes, uma área externa e uma infraestrutura, os quais são separados conforme sua carga sensorial, diferente dos projetos comuns de arquitetura, onde os ambientes se separam por funções. No primeiro setor está presente o bloco administrativo, onde estará previsto todos os serviços "formais", desde cadastros dos pacientes atendidos até mesmo os serviços de organização do espaço.

No segundo setor, encontra-se o bloco de diagnóstico e apoio, onde estão localizadas as salas para atendimento inicial do paciente feito por profissionais especializados e também locais de apoio para a família do paciente, como assistência social e sala de psicologia, onde acontece o atendimento com psicólogas que colaboram de forma positiva na relação entre família e autistas.

A recepção foi localizada na entrada do espaço, sendo direcionada a receber e orientar os usuários; a sala de arquivos, destinada ao armazenamento de pastas com arquivos dos usuários; a sala de segurança, destinada ao monitoramento dos espaços do local como um todo, e coworking, espaço destinado aos responsáveis dos autistas, nele será possível trabalhar e estudar.

No terceiro setor, estão os blocos de terapias de estímulos, zonas que possuem atividades que exigem maiores movimentos e requerem mais estímulos das crianças, com salas separadas de acordo com sua função. Neste bloco não possui banheiros, mas no local de maneira geral eles estão instalados no centro com ligação a área externa.

O bloco de serviço encontra-se no quarto setor, onde se localiza todos os suportes aos funcionários, salas de depósitos, copa e outros ambientes que se enquadram no centro. $\mathrm{Na}$ área externa estão localizadas as atividades de vivência, desenvolvimento e interação entre os pacientes, nesse ambiente estão localizados ambientes como praças, jardim sensorial e alguns ambientes que colaboram para interação e desenvolvimento. No setor de infraestrutura ficaram situados os espaços de suporte ao local, como gerador, espaço 
para colocação de lixos para coleta, gás e estacionamento privado, tanto para pacientes, quanto para os profissionais que trabalharam no local.

Figura 3: Organograma da proposta de projeto.

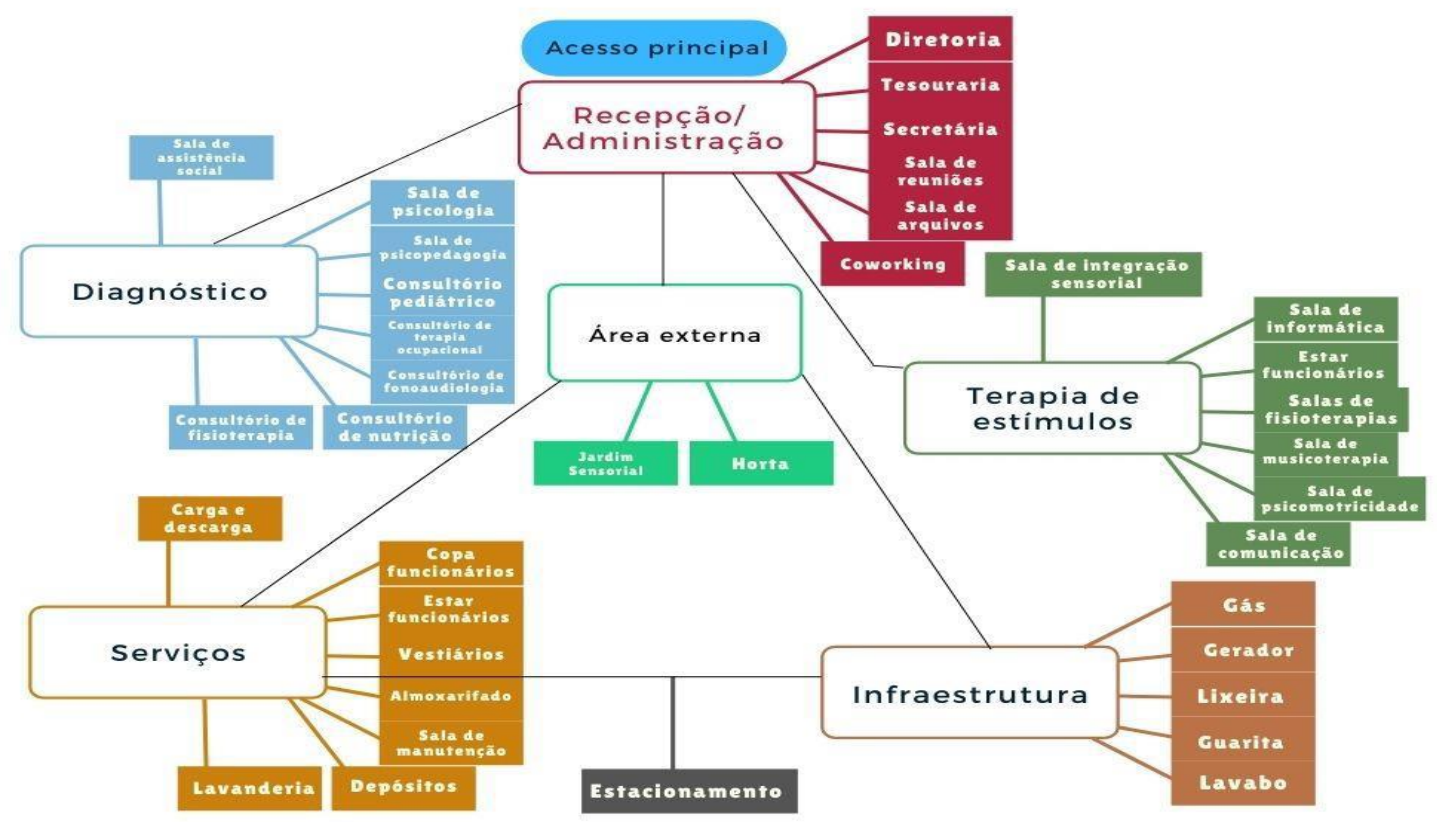

Fonte: Própria autoria, 202I.

Figura 4: Estudo da forma da proposta projetual em perspectiva.

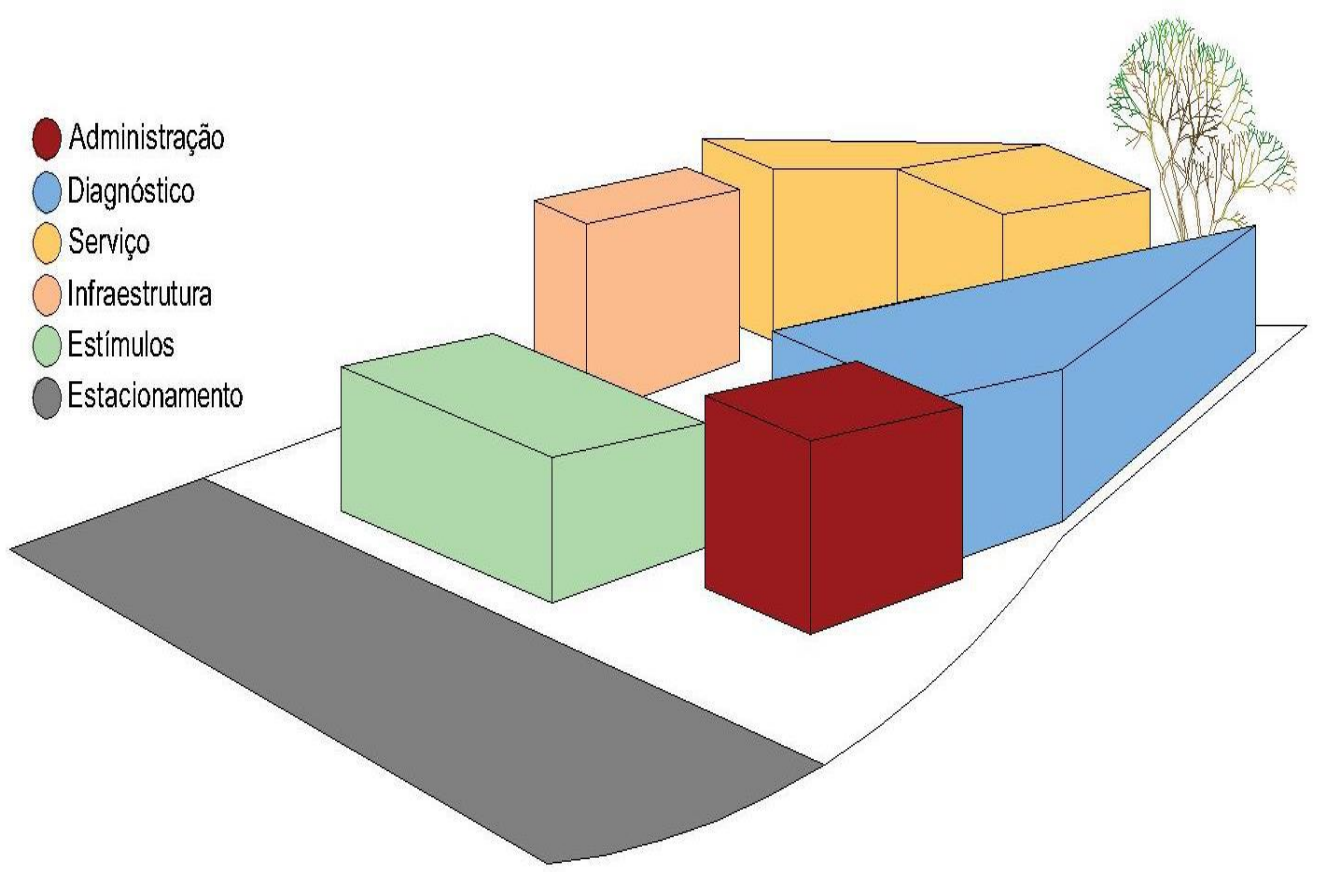

Fonte: Própria autoria, 2021. 
Figura o5: Praça sensorial na proposta de projeto do centro.

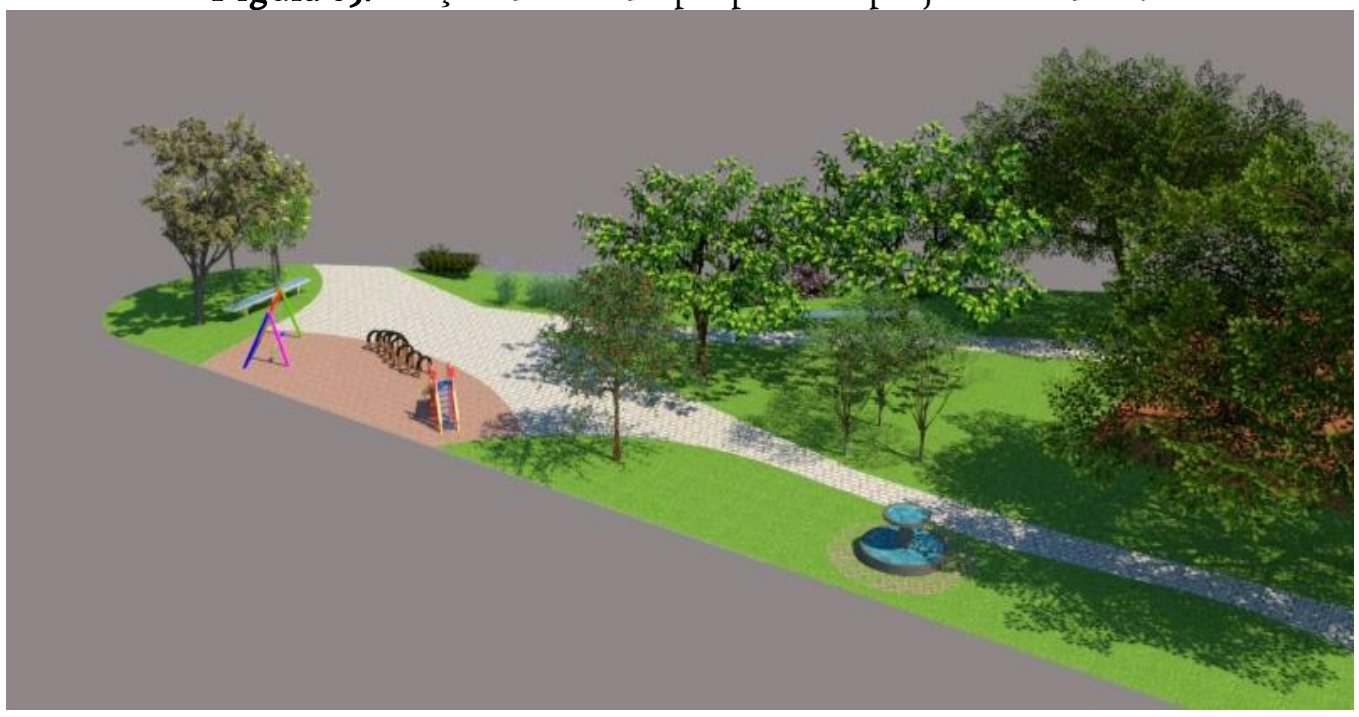

Fonte: Própria autoria, 2021.

\section{CONSIDERAÇÕES FINAIS}

O presente trabalho foi realizado a fim de compreender as principais necessidades dos autistas e de seus familiares, além de entender como a arquitetura pode colaborar positivamente no tratamento e desenvolvimento das pessoas com este transtorno.

Percebe-se nitidamente que o TEA vem ganhando cada vez mais espaço na sociedade como um todo, e devido a esse crescimento, notou-se a necessidade da criação de um centro especializado apenas nesta área, que comportasse e tivesse os designs ideais ao número de autistas no município de Bauru. Sabendo-se que é de extrema importância a interação com a família para o desenvolvimento e que a interação com a sociedade se faz necessária, esse projeto traz uma solução às ausências de suporte para as crianças autistas em Bauru.

O entendimento sobre o autismo em suas características, tipos de tratamentos, percepções, sentidos e a importância da arquitetura nos estímulos e desenvolvimento, foram essenciais para o andamento desta proposta de projeto, assim como a análise realizada em visita técnica para facilitar no entendimento de como funcionam e são organizados os espaços voltados às pessoas com transtorno.

Todo levantamento foi de extrema importância para conhecimento do tema, evidenciando as condutas necessárias que facilitaram as etapas de criação. $O$ estudo das condições do terreno escolhido, assim como a relação com o entorno, fundamentou o 
desenvolvimento das diretrizes projetuais. Foi observada principalmente a importância da relação com o público externo, no quesito do ruído e poluição sonora.

A volumetria e a espacialidade proposta para o local reforçaram a intenção de quebrar a idéia de um ambiente de tratamento ser remetido a um local frio e regrado. A proposta do edifício foi quebrar este paradigma, trazendo a idéia de acolhimento e ao mesmo tempo ter um local em contato com a natureza e com áreas de interação.

A arquitetura tem um papel fundamental no desenvolvimento de todas as pessoas, sejam autistas ou não. Como foi exposto em todo o trabalho as crianças com autismo possuem sensibilidades aos estímulos e de entendimento espacial. Com isso foram adotadas diversas soluções arquitetônicas especificas para colaborar no desenvolvimento e inclusão das pessoas com TEA, e a interação entre os cuidados na troca de conhecimentos sobre o autismo.

\section{REFERÊNCIAS BIBLIOGRÁFICAS}

ARAÚJO, Elaine Cristina Teixeira. Projeto arquitetônico para centro de referência de diagnósticos e tratamento do transtorno do espectro do autismo (TEA) na cidade de Bauru - SP. Trabalho de conclusão do curso de Arquitetura e Urbanismo da Universidade Paulista, Bauru, SP, 2021.

ALOCHIO, Geovana; QUEIROZ, Virgínia. Architecture and a utis m: guidelines for therapeutic spaces. Artigo, VIII ENEAC, Natal, RN, 2020.

AMARAL, Karla Alberini; PEINADO, Hugo Sefrian. Edificações e scolares a cessíveis: aspectos projetuais para atendimento de pessoas com deficiência intelectual e transtorno do espectro autista. In: Encontro Nacional de Tecnologia do Ambiente Construído, i8., 2020, Porto Alegre. Anais... Porto Alegre: ANTAC, 2020.

BRASIL ESCOLA. Autismo na escola: pontos e contrapontos na escola inclusiva. Disponível em: https://monografias.brasilescola.uol.com.br/pedagogia/autismo-naescola-pontos-contrapontos-na-escola-inclusiva.htm Acessado em dezembro de 2021.

CENTERS FOR DISEASE CONTROL AND PREVENTION (CDC). Data \& Statistics on Autism Spectrum Disorder. Disponível em: https://www-cdcgov.translate.goog/ncbddd/

autism/data.html?_x_tr_sl=en\&_x_tr_tl=pt\&_x_tr_hl=ptBR\&_x_tr_pto=op,sc. Acessado em maio de 2021. 
EPIFÂNIO, Aline Garavelo. Autismo e arquitetura: sede para Associação A quarela Pró Autista Erechim- RS. Trabalho final de graduação apresentado ao Depto de Arquitetura e Urbanismo da Universidade da Fronteira do Sul, RS, 2018.

FÉRNANDEZ-ANDRÉS, MI; PASTOR-CEREZUELA, G, CERVERA, Sanz P, et al. A comparative study of sensory processing in children with and without Autism S pectrum disorder in the home and classroom environments. Res Dev Disabil. (2015) 38:202-12. Io.1oI6/j.ridd.2014.12.034.

GUTIÉRREZ, Ana Gentil; GOMEZ,José Luis Cuesta; FERNANDEZ, Paula Rodriguez; et al. Implication of the Sensory Environment in Children with A utism Spectrum Disorder: Perspectives from School. International Journal Environmental Research Public Health. 2021 Jul; 18(14): 7670.

HAMADA, Rafael Seiji. Arquitetura e autismo: a associação dos amigos do autista c omo espaço de acolhimento e orientação para pessoas com transtorno do espectro do au tis mo, na grande Florianópolis. Trabalho de conclusão de curso apresentado ao Departamento de Arquitetura e Urbanismo da Universidade Federal de Santa Catarina, 202I.

INSTITUTO NEURO SABER. Como é a classificação de cores no a utismo. Publicado em 16 de agosto de 2017. Disponível em: https: //institutoneurosaber.com.br/como-eclassificacao-de-cores-no-autismo/. Acessado em abril de 2021.

LAUREANO, Claudia de Jesus Braz. Recomendações projetuais para a mbientes com atendimento de terapia sensorial direcionados a crianças com a utismo. Dissertação apresentada ao Programa de Pós-graduação em Arquitetura e Urbanismo da Universidade Federal de Santa Catarina, 2017.

LOUSADA, Vinicius (2019). Audiência aponta lacuna no a tendimento educacional a alunos com autismo em grau grave. Disponível em: https://www.bauru.sp.leg.br/ imprensa/noticias/audiencia-aponta-lacuna-no-atendimento-educacional-alunos-comautismo-em-grau-grave/ Acessado em janeiro de 2022.

MARANHÃO, Ana Léa. Musicoterapia no Autismo. V.2, N.02 (2020): Revista Eletrônica Humanitaris [106].

MOSTAFA, Magda (2008). An architecture for autism: Concepts of design intervention for the autistic user. Archnet-IJAR: International Journal of Architectural Research, 2(1), i 89 2II.

NOBLE, Beth. The Impact of Indoor Environment Quality on People on the Autism Spectrum. Thesis submitted to Victoria University of Wellington, New Zealand, 2018.

OLIVEIRA, Aldeny Alves. As práxis inclusivas de crianças autistas nas escolas de educação infantil. Publ. Multidisciplinary scientific journal - Núcleo do Conhecimento, 2021. Disponível em: https://www.nucleodoconhecimento.com.br/educacao/as-praxisinclusivas. Consultado em 17 de janeiro de 2021. 
OUELLET, B.; CARREAU, E.; DION, V., et al. Efficacy of Sensory Interventions on School Participation of Children with Sensory Disorders: A Systematic Review. AJLM., 2021; 15:75-83. doi: 10.1177/1559827618784274.

POSAR, A.; VISCONTI, P. Sensory abnormalities in children with a utismo spectrum disorder. Rio de Janeiro, Jornal de Pediatria, v. 94 n.4, p.342-350, 2018.

RAFAGNIN, Leticia; DEGANUTTI, Paola Souza Gomes. Projeto Sentir: Centro de apoio para crianças e jovens autistas. Revista Technoeng, Centro de Ensino Superior dos Campos Gerais - CESCAG, 22ª Edição / Jul - Dez de 2020.

SASSAKI, Romeu Kazumi (2008). Questões semânticas sobre as deficiências visual e intelectual na perspectiva inclusiva. Revista Reação, São Paulo, ano XI, n. 62, p ıo-I6.

SILVA, Juliana Christiny Mello da; BRASIL, Paula de Castro; ROLA, Sylvia Meimaridou. Aspectos do conforto ambiental como resposta às alterações sen soriais dos educandos com TEA. Artigo, XVIII Encontro Nacional de Tecnologia do Ambiente Construído. Porto Alegre, RS, 2020.

SOUZA, Beatriz Góes de. Centro de atividades para autistas na cidade de Bauru, SP. Trabalho de conclusão apresentado ao curso de Arquitetura e Urbanismo da Universidade Paulista, campus Bauru, 2021.

VASCONCELlOS, Maria Eduarda Leitão. Para u ma arquitetura inclusiva: Proposta de intervenção em uma Escola Básica no Porto para o desenvolvimento da criança au tis ta. Dissertação de Mestrado apresentada à Faculdade de Arquitetura da Universidade do Porto, Portugal, 2020.

VITTUDE. TRANSTORNO DO ESPECTRO AUTISTA OU AUTISMO. Publicado em o8 de abril de 2018. Disponível em:https://www.vittude.com/blog/transtorno-doespectro-autista-ouautismo/\#: :text=O\%20autismo\%20\%C3\%A9\%20apenas\%2oum,gerando\%20na\%2orotina\%20do\%2oindiv\%C3\%ADduo. Acessado em março de 202I. 